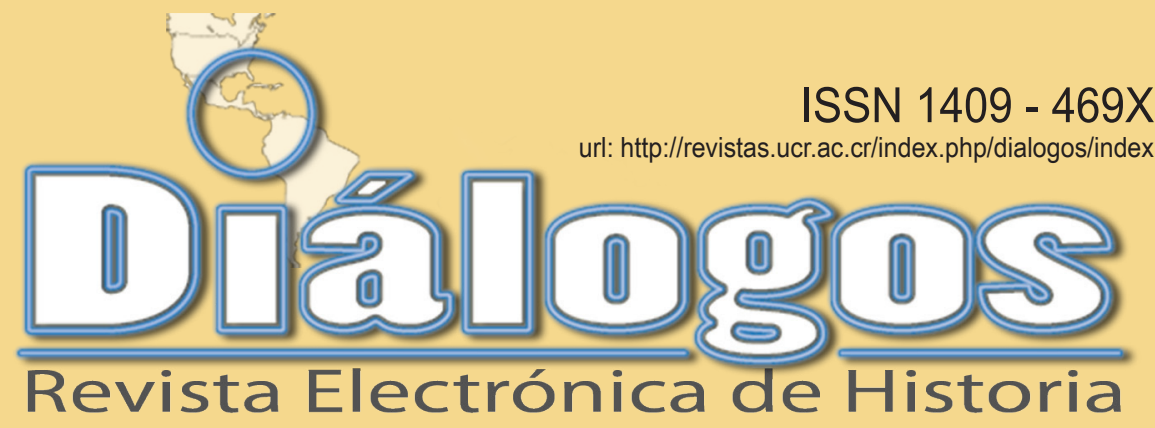

Escuela de Historia. Universidad de Costa Rica Volumen 15 Especial Región Occidente de Costa Rica - Octubre, 2014

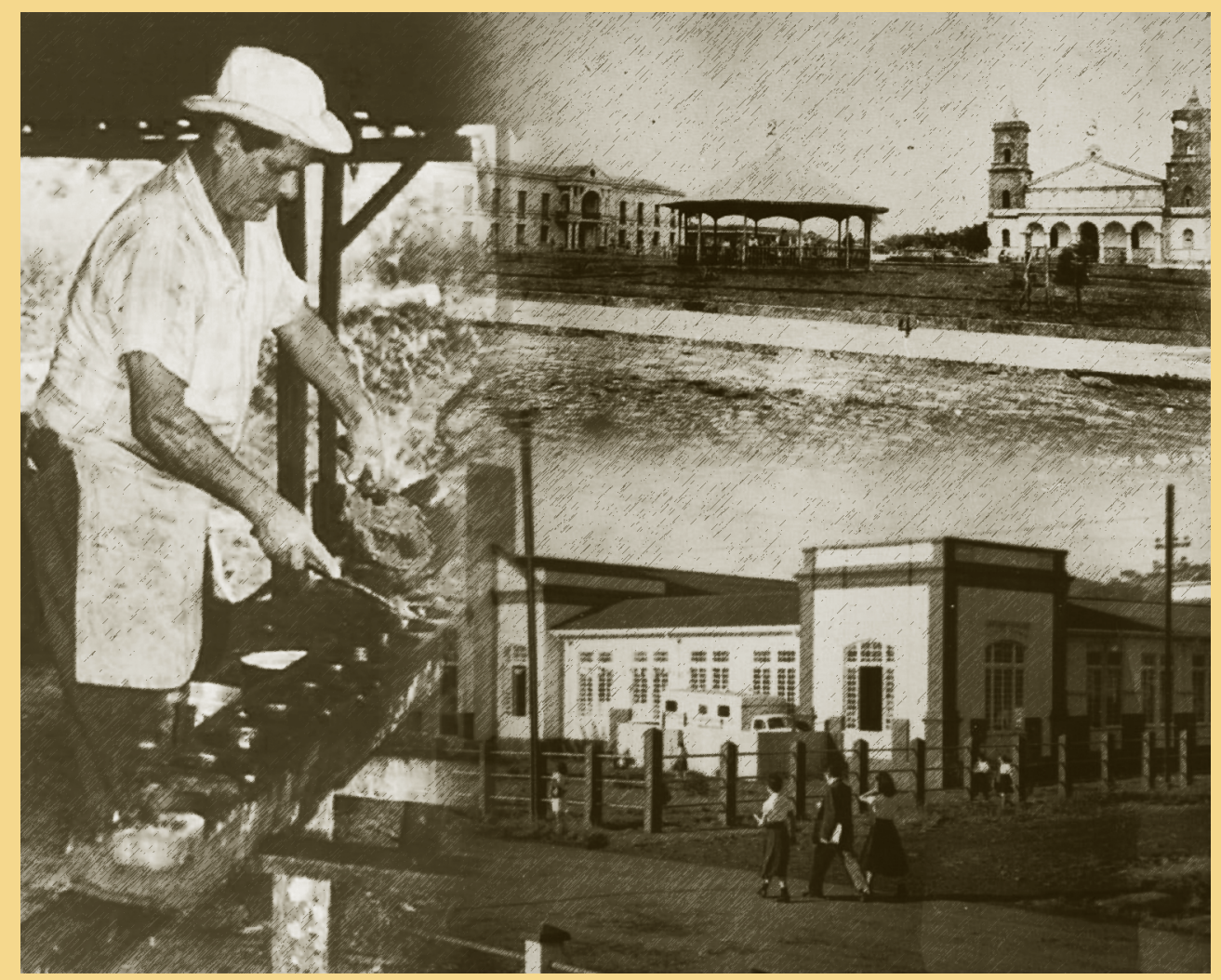

Director de la Revista: Dr. Juan José Marín Hernández juan.marinhernandez@ucr.ac.cr

Editor académico: Dr. David Díaz Arias - david.diaz@ucr.ac.cr

Editores invitados: M.Sc. William Solórzano Vargas - william.solorzano@ucr.ac.cr

M.Ed. Maynor Badilla Vargas - mainor.badilla@ucr.ac.cr

Editora técnica: M.Sc. Marcela Quirós G. - marcela.quiros@ucr.ac.cr 
Dr. Juan José Marín Hernández, Catedrático. Director del Centro de Investigaciones Históricas de América Central. Universidad de Costa Rica. Costa Rica. juan. marin@ucr.ac.cr

Dr. David Díaz Arias: Catedrático. Historia Política, Director del posgrado de Historia y Docente de la Escuela de Historia, Universidad de Costa Rica, Costa Rica.david.diaz@ucr.ac.cr

Dr. Ronny Viales Hurtado. Catedrático. Historia Económica y Social. Universidad de Costa Rica. Director de la Escuela de Historia. Costa Rica. ronny. viales@ucr.ac.cr

MSc. Francisco Enríquez. Historia Social. Universidad de Costa Rica. Costa Rica. francisco.enriquez@ucr. ac.cr

Dra. Ana María Botey. Historia de los movimientos sociales. Universidad de Costa Rica. Costa Rica. abotey@gmail.com

\section{Miembros del Consejo Asesor Internacional:}

Dr. José Cal Montoya. Universidad de San Carlos de Guatemala. Guatemala. jecalm@correo.url.edu.gt

Dr. Juan Manuel Palacio. Universidad Nacional de San Martín. Argentina.jpalacio@unsam.edu.ar

Dr. Eduardo Rey. Universidad de Santiago de Compostela. España. ereyt@usc.es

Dr. Heriberto Cairo Carou. Departamento de Ciencia Política y de la Administración III - Universidad Complutense de Madrid. España. hcairoca@cps.ucm.es

Dra. Rosa de la Fuente. Departamento de Ciencia Política y de la Administración III Universidad Complutense de Madrid. España. rdelafuente@cps. ucm.es

Dr. Javier Franzé. Departamento de Ciencia Política y de la Administración III Universidad Complutense de Madrid. España. javier.franze@cps.ucm.es

Dr. Jaime Preciado Coronado Departamento de Estudios Ibéricos y Latinoamericanos. Universidad de Guadalajara. México.japreco@hotmail.com

Dr. Gerónimo de Sierra. Vicerrector de la Universidade Federal da Integração Latino-Americana (UNILA) y Departamento de Sociología, Facultad de Ciencias

Sociales de la Universidad de la República. Uruguay. geronimo@fcs.edu.uy

Dr. Antonio Palazuelos. Departamento de Ciencia Política y de la Administración III - Universidad Complutense de Madrid. España. palazuelosa@cps. ucm.es

Dr. Werner Mackenbach. Universidad Potsdam. Alemania.werner.mackenbach@uni-potsdam.de

Dr. Guillermo Castro. Ciudad del Saber Panamá. Panamá.gcastro@cdspanama.org

Dra. Natalia Milanesio. University of Houston. Estados Unidos.nmilane2@Central.UH.EDU

Dr. Ricardo González Leandri. Consejo Superior de Investigaciones Científicas - España. España. rgleandri@gmail.com

Dra. Mayra Espina. Centro de Estudios Psicológicos y Sociológicos, La Habana. Cuba.mjdcips@ceniai.inf.cu

Dra. Montserrat Llonch. Departamento de Economía e Historia Económica Universidad Autónoma de Barcelona. España. montserrat.llonch@uab.es

Dra. Estela Grassi. Universidad de Buenos Aires. Argentina. estelagrassi@gmail.com

Dra. Yolanda Blasco. Universidad de Barcelona. España. yolandablasco@ub.edu

Dr. Alfredo Falero. Departamento de Sociología. Universidad de la República. Uruguay. alfredof@adinet. com.uy

Portada:

Fotografía: ( Collage "Campesinos en la producción de dulce en un trapiche de Rincón de Mora, Ran Ramón, 1987" ; "Panorámica del Antiguo Palacio Municipal, Antigua Iglesia, Parque y Kiosco de San Ramón, hacia 1920; y Escuela Jorge Washinton, San Ramón hacia 1955). Estas fotografías pertenecen a la Colección Fotográfica del Museo Regional de San Ramón- UCR. Montaje fotográfico: Lic. Juan Gabriel Madrigal Cubero ).

\section{Equipo Técnico Editorial:}

Diagramación y

Edición técnica:

M.Sc. Marcela Quirós Garita. marcela.quiros@ucr.ac.cr

Soporte técnico: Kevin Trejos Vargas

Revisión filológica: Baruc Chavarría Castro 
"Diálogos Revista Electrónica de Historia" se publica desde octubre de 1999.

\section{Diálogos está en los siguientes repositorios:}

Dialnet

http://dialnet.unirioja.es/servlet/

revista?tipo_busqueda=CODIGO\&clave_revista $=3325$

\section{Latindex}

http://www.latindex.unam.mx/larga.php?opcion=1\&folio=12995;

\section{UCRindex}

http://www.revistas.ucr.ac.cr

\section{Scielo}

http://www.scielo.cll

\section{eRevistas}

http://www.erevistas.csic.es/

\section{REDALYC}

http://redalyc.uaemex.mx/src/inicio/FrmBusRevs2.jsp?iEdoRev=2\&cvepai=11;

\section{LANIC}

http://lanic.utexas.edu/la/ca/cr/indexesp.html;

Repositorio de Revistas Universidad de Costa Rica

http://www.latindex.ucr.ac.cr/

Directorio y recolector de recursos digitales del

Ministerio de Cultura de España

http://roai.mcu.es/es/inicio/inicio.cmo

DOAJ Directory of open access \& Hybrid journals

http://www.doaj.org/doaj?func=byTitle\&hybrid=1\&query=D

Biblioteca de Georgetown

http://library.georgetown.edu/newjour/d/msg02735.htm

Asociación para el Fomento de los Estudios Históricos en Centroamérica

http://afehc.apinc.org/index.php?action=fi_aff\&id=1774

Universidad de Saskatchewan, Canadá

https://library.usask.ca/ejournals/view/1000000000397982

Monografias

http://www.monografias.com/Links/Historia/more12.shtml

\section{Hispanianova}

http://hispanianova.rediris.es/general/enlaces/hn0708.htm

Universidad del Norte, Colombia

http://www.uninorte.edu.co/publicaciones/memorias/enlaces.htm

Universidad Autónoma de Barcelona

http://seneca.uab.es/historia/hn0708.htm

Repositorio Invenia - Gestión del Conocimiento http://www.invenia.es/oai:dialnet.unirioja.es:ART0000086144

\section{Enlace Académico}

http://www.enlaceacademico.org/biblioteca/

revistas-en-formato-digital-centroamerica/

\section{Electronic Resources}

http://sunzi1.lib.hku.hk/ER/detail/hkul/3987318

Revistas académicas en texto completo http://web.prw.net/ vtorres/

Diálogos se anuncia en las siguientes instituciones y sitios académicos:

Maestroteca

http://www.maestroteca.com/detail/553/dialogos-revista-electronica-de-historia.html

Biblioteca de Georgetown

http://library.georgetown.edu/newjour/d/msg02735.htm

Asociación para el Fomento de los Estudios Históricos en Centroamérica

http://afehc.apinc.org/index.php?action=fi_aff\&id=1774

Universidad de Saskatchewan, Canadá

https://library.usask.ca/ejournals/view/1000000000397982

Monografias

http://www.monografias.com/Links/Historia/more12.shtm

Hispanianova

http://hispanianova.rediris.es/general/enlaces/hn0708.htm

Universidad del Norte, Colombia

http://www.uninorte.edu.co/publicaciones/memorias/enlaces.html

Universidad Autónoma de Barcelona

http://seneca.uab.es/historia/hn0708.htm

Repositorio Invenia - Gestión del Conocimiento

http://www.invenia.es/oai:dialnet.unirioja.es:ART0000086144

Enlace Académico

http://www.enlaceacademico.org/biblioteca/

revistas-en-formato-digital-centroamerical

\section{Electronic Resources}

http://sunzi1.lib.hku.hk/ER/detail/hkul/3987318

Revistas académicas en texto completo http://web.prw.net/ vtorres/

Diálogos Revista de Historia está catalogada por Sherpa Romeo como una revista verde.

La revista electrónica Diálogos es financiada por Vicerrectoría de Investigación de la Universidad de Costa Rica

Citado en: Scielo Dialnet - eRevistas - UCRindex Latindex - REDALYC - DOAJDirectorio y recolector de recursos digitales del Ministerio de Cultura de España

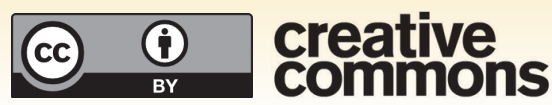




\title{
EL NEOCLASICISMO LLEGA A LA RURALIDAD NACIONAL EN EL SIGLO XIX: EL PALACIO MUNICIPAL DE SAN RAMÓN
}

\section{NEOCLASSICISM ARRIVES TO THE NATIONAL RURAL LIFE IN THE NINETEENTH CENTURY: THE MUNICIPAL PALACE OF SAN RAMON}

Lissy Marcela Villalobos Cubero

\begin{abstract}
Palabras claves
Población rural, San Ramón, municipalidad, arquitectura, ideología liberal.

\section{Keywords}

Rural population, San Ramon, municipalities, architecture, liberal ideology
\end{abstract}

Fecha de recepción: 30 de julio, 2013 - Fecha de aceptación: 22 de abril, 2014

\begin{abstract}
Resumen
El presente texto incluye un estudio sobre la arquitectura con influencia neoclásica en un área rural costarricense. Concretamente el sitio se ubica en el cantón de San Ramón de Alajuela y temporalmente corresponde al tránsito entre el siglo XIX y XX. El objetivo de la investigación radicó en hacer una lectura de la forma en que la ideología liberal así como el poder político-económico llegan a ser reflejados a través del arte, concretamente mediante la arquitectura civil, que se observa en el que era edificio municipal y el contexto que influyó en su propia construcción. Para desarrollar dicha investigación se consultaron fuentes municipales y del archivo que posee el Museo Regional de San Ramón, además de fuentes secundarias.
\end{abstract}

\begin{abstract}
The text includes a study about the architecture with neoclassical influence in a rural area. This place is located on community named San Ramón of Alajuela, Costa Rica; between nineteenth and twentieth centuries. The object of investigation was to read the forms how the liberal ideology, politic-economic power, is represented through the arts, specifically on civil architecture, with the municipal building and the context that influenced it. For this investigation were consulted fundamentally: minutes of municipal archives; documentation of archive from local museum and other texts about theme.
\end{abstract}




\title{
EL NEOCLASICISMO LLEGA A LA RURALIDAD NACIONAL EN EL SIGLO XIX: EL PALACIO MUNICIPAL DE SAN RAMÓN
}

\author{
"No debemos olvidar nunca que el estilo, al igual que cualquier uniforme, \\ es también una máscara que esconde tanto como revela"
} Gombrich (1999, p. 261)

\section{INTRODUCCIÓN}

Los trabajos que se han llevado a cabo en nuestro país sobre la relación entre las obras arquitectónicas y la dinámica sociopolítica y económica del siglo XIX, se han enmarcado principalmente en la zona del "Valle" Central, específicamente en los centros urbanos de San José, Heredia, Cartago y Alajuela.

En ese sentido, es menester destacar la labor realizada en el texto de Elizabeth Fonseca y José Enrique Garnier (1998), donde se entrelaza el conocimiento de la historia con el análisis de las distintas edificaciones nacionales a través del tiempo, texto denominado Historia de la Arquitectura en Costa Rica, que al mismo tiempo incluye valiosos aportes en el reconocimiento de los estilos constructivos durante el siglo XIX, como lo presentan Ofelia Sanou y Florencia Quesada (1998) en su apartado sobre "Herencia, ruptura y nuevas expresiones arquitectónicas (1841-1870)".

Tales autoras tienen otros trabajos relevantes por separado y en el campo que nos ocupa han venido a contribuir con el conocimiento sobre el desarrollo de la arquitectura religiosa, agroindustrial, así como el crecimiento y estructura de la capital costarricense (San José).

Así pues, Sanou (2001) ha publicado Arquitectura e historia en Costa Rica: templos parroquiales en el Valle Central, Grecia, San Ramón y Palmares 18601914, explorando en detalle el contexto religioso del sector occidental de la Meseta Central y los estilos involucrados en la materialización de espacios religiosos. Además, esta investigadora ha contribuido con el conocimiento del espacio rural y la manera en que eran ordenados espacios y construcciones en las haciendas, realizando un estudio más orientado a la relación entre arquitectura y funcionalidad económica (Sanou, 2002).

Mientras que Florencia Quesada se ha enfocado en la provincia de San José. En su trabajo sobre el Barrio Amón (2001), permite observar la estructura habitacional en un entorno de élite capitalina a inicios del siglo XX, vinculándolo con las prácticas sociales de sus habitantes. Y en el texto posterior que titula Modernización entre cafetales (2011), estudia el crecimiento josefino entre 1880 
y 1930 y la incorporación de los ideales liberales sobre orden y progreso en la estructuración del entorno urbano.

Relacionados con esa misma línea de investigación y para un periodo similar, también encontramos los trabajos de Carlos Altezor (1986) con su análisis sobre arquitectura urbana en Costa Rica entre 1900 y 1950; los textos de Rosa Malavassi (Malavassi y Jiménez, 2006; Malavassi, 2012) sobre el cantón de La Unión y el edificio Pirie, ambos enmarcados geográficamente en el cantón de Cartago; además del aporte de Gerardo Vargas y Carlos Zamora acerca del desarrollo urbano y el tema patrimonial en el distrito del Carmen en la capital, entre la segunda mitad del siglo XIX y la década de 1930 (Vargas y Zamora, 1999).

Bajo otros ejes de análisis están los aportes de Luis Ferrero (1986) en Sociedad y Arte en la Costa Rica del siglo XIX; Arnaldo Moya (2008-2009) y sus aportes en "Arquitectura e Interpretación Histórica"; quienes no se enfocan en una comunidad específica, edificio o entorno (urbano/rural), sino que plantean estudios que vayan más allá y funcionen como un insumo para comprender los contextos regionales y nacionales en torno al estudio de la historia de la arquitectura.

Precisamente es en el texto de Moya que puede ubicarse la discusión sobre la escasa existencia de estudios que vayan más allá del espacio capitalino, pues se aboca a reconocer la arquitectura en otras provincias como lo hace con "Arquitectura tradicional en la bajura guanacasteca" (Moya, 2008-2009, p. 337), de Ligia Franco y Lucía Riva, por ejemplo.

Concretamente, sobre el sector que nos interesa en este artículo, área que hoy constituye el cantón de San Ramón, otrora periferia oeste del centro del país, lo que más ha sido analizado es su templo parroquial, pues el edificio que acá nos ocupa - el Palacio Municipal - tiene adjudicada solamente una investigación corta (reseña), realizada por Luis Fernando González (1995), donde además no se da detalle del estilo arquitectónico como lenguaje social ${ }^{1}$.

A raíz de ello, el presente artículo se perfila esencialmente como un esfuerzo por hacer una lectura de la historia a partir de la iconografía, plasmada en la arquitectura civil; un edificio que funciona como uno de los ejes del pueblo ramonense (ver Figura 1) entre las dos últimas décadas del siglo XIX y las dos primeras del siglo XX, ya que a la luz de la construcción del Palacio Municipal de la localidad se hace posible observar la transformación que sufre un espacio rural y remoto, el cual poco a poco pasa a establecerse como un sector económicamente dinámico, a su vez influenciado por la economía nacional y vinculado a los conflictos políticos durante el periodo de auge del Estado liberal y la consolidación de la nación costarricense.

Las fuentes primarias utilizadas en la investigación fueron las actas municipales de San Ramón de los años 1870 a 1890, que se encuentran en el 


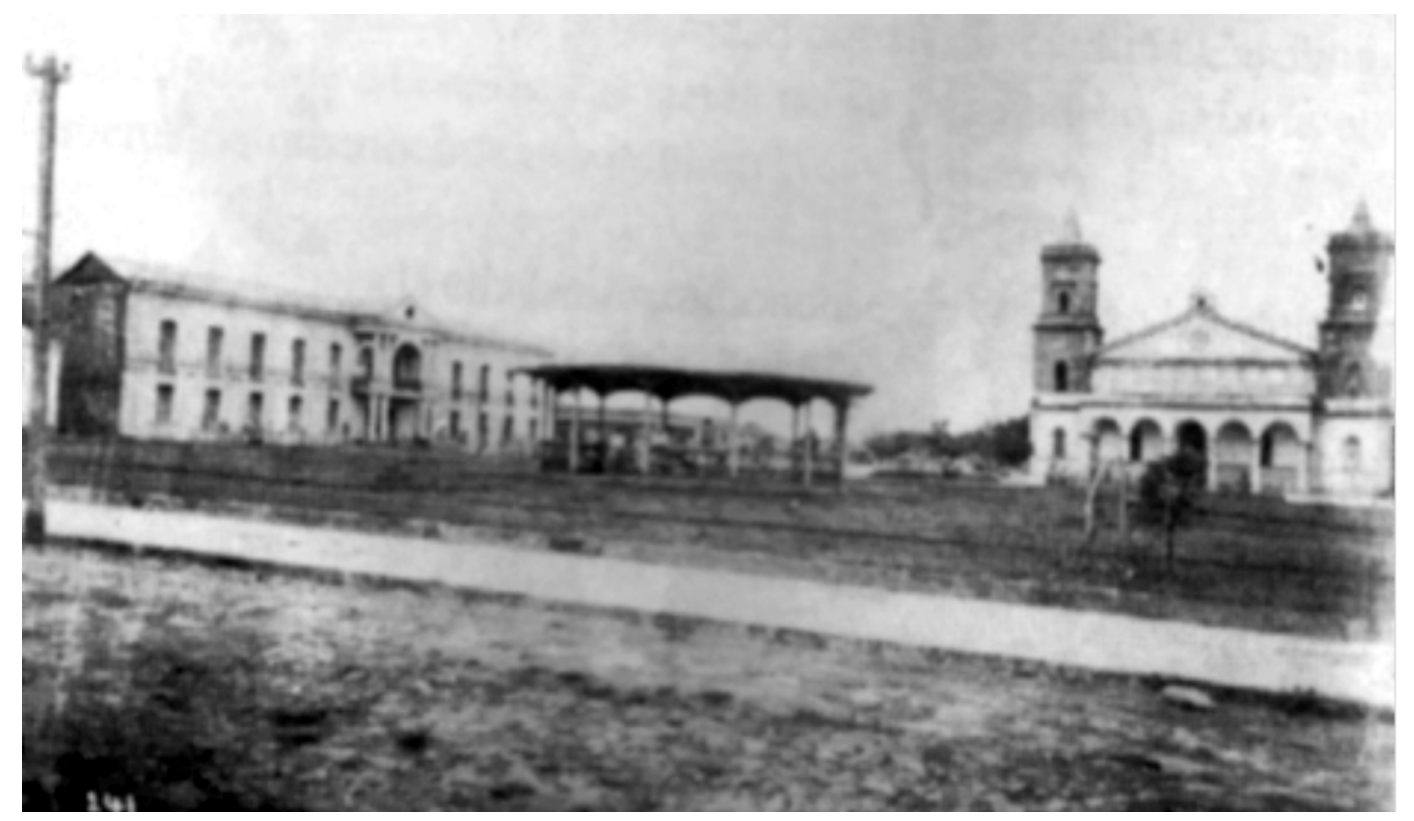

Figura 1. Palacio Municipal de San Ramón. (Año desconocido). Se puede notar que solo existían el templo católico y el quiosco en ese punto central de la comunidad. Finales del siglo XIX e inicios del siglo XX.

Fuente: Museo de San Ramón. Fotografía.

Archivo Nacional, además de correspondencia sobre el desarrollo de la obra, planos originales y copias del edificio, así como fotografías del Palacio Municipal. Estas fuentes se obtuvieron tanto del Archivo Nacional como del Museo Regional de San Ramón, con ellas se hizo posible una aproximación a los detalles de la edificación $\mathrm{y}$ los elementos que intervinieron en su proceso constructivo.

Por su parte, las fuentes secundarias involucran libros, tesis, artículos de revista e informes de investigación que funcionaron como insumos para comprender mejor el contexto nacional, regional y local desde finales del siglo XIX y XX. Es así que se cuenta entonces con trabajos sobre la arquitectura costarricense de la época, el cantón de San Ramón en sus inicios y el periodo liberal en Costa Rica. Además de los trabajos de corte más teórico sobre las maneras de analizar el arte y concretamente la arquitectura como formas de expresión social, económica y cultural.

En términos teóricos, consideramos que "los arquitectos ponen en práctica aquello que les es permitido, diseñan construcciones, pero no el valor de lo que acontezca en sus espacios" (Mielgo, 2006, p.437); por ende, el significado de la arquitectura pasa inevitablemente por el lugar del acontecimiento y el momento en que se da. Esta investigación se incluye dentro de las tendencias de la historia del arte y la historia socio-cultural que interpretan la arquitectura como un objeto 
sometido a las leyes de la comunicación (Vera y Sánchez, 1985, pp. 23-45); es decir, se reconoce como una creación social que cumple una función social y que puede, por tanto, ser leída y entendida a través del lenguaje que expresa, observando los rasgos ideológicos que intervienen en ella, las condiciones económicas y políticas a las que responde y el modo en que funciona de cara a su entorno. Además de su condición como representación de poder, en lo que coincidimos con Rosa Malavassi cuando cita a Concepción de la Peña, para quien "hablar del poder en arquitectura implica analizarla como hecho fenomenológico; considerar el uso del lenguaje artístico como transmisor ideológico o la elección de los materiales por su valor o por su simbolismo; indagar cuáles son las estrategias para conseguir los objetivos; estudiar qué la distingue o identifica como perteneciente a una tipología, a una institución o estirpe familiar" (Malavassi, 2012, p. 942).

La metodología seguida en este trabajo consistió en llevar a cabo un análisis de contenido, tanto en actas como en la correspondencia y las fotografías, identificando categorías como arquitectura y poder político; arquitectura y economía; arquitectura y progreso; arquitectura y espacio geográfico; de manera que una serie de palabras y frases claves asociadas a cada una de tales categorías pudiesen ser reconocidas, para luego ser trianguladas con el resto de fuentes. Además se hizo un seguimiento genealógico y prosopográfico de algunos individuos claves que aparecen recurrentemente en los datos municipales de la época y en las fuentes secundarias, con la intención de reconocer sus filiaciones económicas y su origen dentro del área estudiada, todo ello con la intención de interpretar la influencia que pudieran tener en la materialización de un edificio como el Palacio Municipal.

En primera instancia, se da a conocer, de manera breve, el proceso de formación del cantón de San Ramón, con la intención de contextualizar el impulso dado a una obra de infraestructura poco común para un sitio aún inhóspito. Se pretenderá determinar las características de una población distante del centro de poder, pero al mismo tiempo creciendo como receptora de inmigrantes nacionales y extranjeros. En el segundo apartado se lleva a cabo una descripción breve del diseño inicial del edificio municipal, así como un abordaje más amplio sobre sus características como obra construida y se incorpora también un apartado para examinar el costo de la obra. Por último, se presenta un análisis sobre el estilo y el papel de los grupos de poder socioeconómico y político en esta.

\section{SAN RAMÓN EN LA SEGUNDA MITAD DEL SIGLO XIX, UN ESPACIO REMOTO}

Costa Rica hacia finales del siglo XIX se estructuraba como un país de escaso desarrollo urbano, donde era la capital el principal polo de crecimiento poblacional, 
industrial y comercial. El resto del territorio nacional estaba orientado básicamente a la agricultura y ganadería, además de importantes proporciones de bosque y áreas sin denunciar. Con un Estado basado en la ideología liberal, común en esa época, la intención de poner en práctica la lógica del crecimiento del mercado, la importancia de la propiedad privada, el progreso y el orden, se fueron incentivando los procesos migratorios hacia territorios del interior del país, de la mano con el uso de terrenos denunciados como propios y su consiguiente explotación agropecuaria fundamentalmente (Salazar, 1990; Vargas, 1989; Botey, 1994; Silva, 1991; Viales, 2000).

Ese proceso de colonización agrícola se generó también en el sector occidental de la Meseta Central, en el contexto que retrata Mario Samper cuando estudia ese fenómeno para nuestro país:

\begin{abstract}
Entre las décadas intermedias del siglo XIX y mediados del XX, la sociedad rural costarricense sufrió cambios muy significativos asociados a la colonización de la mayor parte del territorio nacional, al incremento natural de la población y la inmigración, al desarrollo paralelo y entrelazado de la producción en unidades productivas domésticas y haciendas, y al replanteamiento de las relaciones socioeconómicas y sociopolíticas. En gran medida el crecimiento de la producción agraria durante este período fue extensivo, basado en la incorporación de más tierra y una cantidad similar de trabajo por unidad de superficie, pero también hubo variaciones sustanciales en la organización técnica y social del trabajo (Samper, 2003, pp. 81-104).
\end{abstract}

Ello incrementó la cantidad de poblados a nivel nacional y a su vez la implantación de cierta dinámica política y social a lo interno de esas comunidades, que ya para la primera mitad del siglo XX estaban mejor articuladas y comenzaban a incluir algunos elementos representativos de la modernización que vivía América Latina en la época.

El contexto de los poblados es fundamental para entender el desarrollo de su infraestructura. No es posible entender el significado que puede tener una construcción neoclásica en San Ramón a finales del siglo XIX si no estudiamos primero cómo era esa comunidad en ese momento. De ahí que hemos de hacer un breve recorrido histórico que permita retratar su origen como cantón.

La comunidad de San Ramón de los Palmares se configuró en el sector oeste de la Meseta Central costarricense (ver Figura 2), a partir de la inmigración de individuos durante las décadas de 1840-1850 principalmente, quienes, de acuerdo a Carolyn Hall (1984), se vieron obligados a adentrarse en la ocupación de tierras de frontera agrícola en las cuales establecerse, esto debido a la presión que el crecimiento demográfico generó sobre dicho bien en la Región Central. 
Por su parte, Fournier (1994) es más específico y determina cuatro sitios de procedencia para los grupos de personas que se convirtieron en fundadores del lugar: "tenemos un grupo procedente de Alajuela y Heredia (incluyendo a San Antonio de Belén) y que agrupa a los Alvarado Arrieta y Alvarado Bermúdez, Lobo Loría, Rodríguez Sancho, Vargas Alfaro, Villalobos Solórzano... El segundo grupo estuvo constituido por los que llegaron procedentes de San José: Rodríguez Reyes (Zeledón), Paniagua Astúa, Mora Aguilar, Zeledón (Reyes)... y un tercer grupo estaba formado por individuos, probablemente ya asentados en Sabana Larga (Atenas): Brenes, Ruiz y Vega" (pp. 5-7).

De esta manera, muchas de estas familias adquirieron extensas propiedades para dedicarlas a producir (con ganadería, caña de azúcar o café) y por medio de vínculos matrimoniales lograron mantener cierta estabilidad económica.

Los habitantes, en vista de su lejanía (acentuada por el mal estado de las vías de comunicación) y dificultad para acceder a los servicios acostumbrados, manifestaron su inquietud en una petición vecinal fechada con sello de 1855-1856 en la que se reconocía que San Ramón no era "ya una miserable aldea, és una población que si no ahora muy pronto competirá en riqueza y hermosura con algunas antiguas Ciudades del país: pide un templo regular con su Casa Cural, un edificio para cabildo otro para [*ilegible] elementos para formar los demás edificios públicos que se requieran",2.

Posteriormente, en $1856^{3}$ el pueblo se convirtió en cantón, lo que implicaba contar con su propia representación municipal, abriéndose así el espacio para que

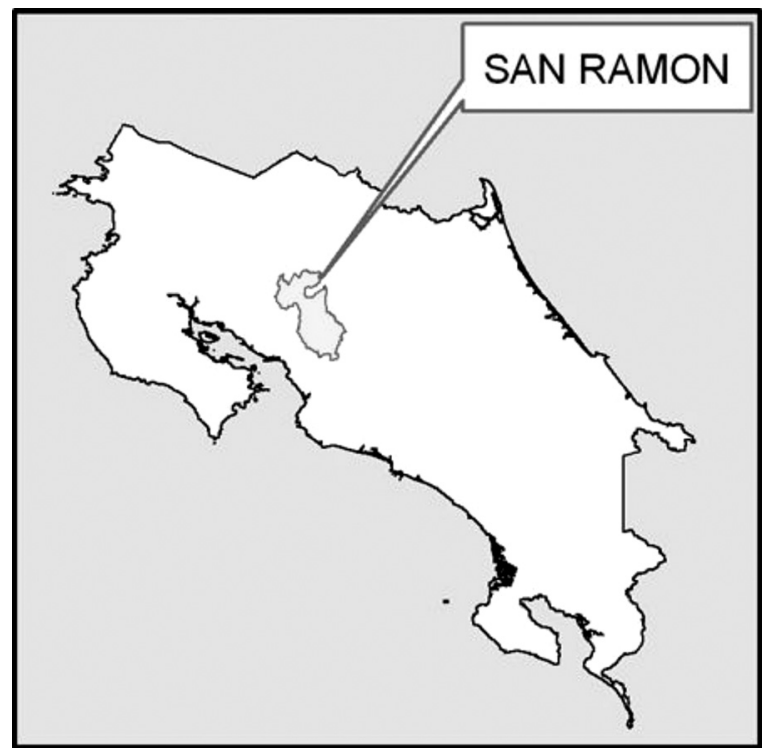

Figura 2. Mapa de ubicación del cantón de San Ramón. Fuente: Municipalidad de San Ramón. Imagen. 
los pobladores prominentes empezaran a vincular el área con la vida política y económica del resto del país, tal como lo hicieron los miembros de la familia Acosta ${ }^{4}$. Mientras otros pondrían el acento en el campo cultural, como la escultura religiosa de Lico Rodríguez (1833-1901), la lírica de Lisímaco Chavarría (18781913) y en el área de las ciencias los aportes de Alberto Manuel Brenes (18701948). De manera que se iba perfilando el naciente cantón como un entorno algo prolífico en el desarrollo de las artes, la política y las ciencias.

Es fundamental hacer un reconocimiento de los individuos extranjeros que empezaron a establecerse en el sector, a partir de la década de 1860, pues su conocimiento de otras ciudades iba a influir en los intereses posteriores del poblado. Tales inmigrantes se dedicaron a actividades agropecuarias y comerciales, llegando a constituirse como solventes familias.

Siguiendo a Quesada (1996, pp. 18-19), los principales foráneos llegados a San Ramón durante las últimas cuatro décadas del siglo XIX, fueron Leonardo Steller Wallen, quien se dice provenía de Alemania y estableció un aserradero. Otro alemán es Luis Hine, quien llegó en 1865 y Manuel Caballero, que venía de Colombia y se dedicó a labores del agro (caña de azúcar). Por su parte, Ascensión Moncada llegó de Nicaragua en 1880 y se dedicó a la explotación de minas de oro, "la mina de Moncada" (Pineda, 1983). Así también arribó al cantón a partir de 1870, el yugoslavo Francisco Orlich Ziz, quien estableció una tienda y una finca sembrada de cabuya e instaló una fábrica para procesarla, además de la obtención de muchas otras propiedades (Castro y Willink, 1989). En ese año también llegaron Agustín Pipper y Agustín Sagot, el primero alemán, el otro francés, ambos instalaron tiendas en el "centro" del cantón.

Además hay que tomar en cuenta lo relevante que fue la llegada de Julián Volio Llorente a la zona, el cual fue enviado en 1880 como "reo político" o exiliado a ese aislado sector del país, aunque ya poseía una finca en el sector e incluso había promovido la creación de una biblioteca pública en 1879. Con Volio Llorente vienen muchas familias ilustres a San Ramón, de las cuales, ciertos miembros colaboraron como docentes en las escuelas, tal es el caso de algunos individuos de apellidos Gutiérrez y Bolandi (Quesada, 1996, pp. 137-138; Cambronero, 2001, p. 29).

Sin embargo, San Ramón, a pesar de un manifiesto crecimiento demográfico - pasó de 5.045 habitantes en 1864 a 9.928 en 1892 (Hernández, 1985, pp. 53, 67) - y una curiosa pujanza cultural, mantenía siempre una geografía de carácter rural con terrenos sembrados y áreas de potrero en el centro del cantón, así como caminos de tierra.

Eso contrastaba con la formación progresiva de un grupo socialmente diferenciado de importante poder económico en el lugar, la existencia de algunas escuelas 
(separadas según el sexo), una biblioteca pública, un alumbrado basado en faroles de canfín en las esquinas de sus escasas calles (Quesada, 1996) ${ }^{5}$ y un edificio municipal en construcción.

Fue precisamente esa población que se configuró como una naciente burguesía local, según Castro y Willink (1989), la que formó parte de los gobiernos locales en las últimas décadas del siglo XIX e intervino en la demanda de un palacio municipal, cuyo diseño fue encargado a un ingeniero alemán recién radicado en Costa Rica. La obra debía obedecer a las condiciones de modernización que se daban en poblados más desarrollados, fue planeada entonces dentro de las corrientes estilísticas de la época para la construcción de edificios estatales: con corte neoclásico; donde la sobriedad, la imponencia de las dimensiones (respecto a su entorno) y las estructuras al estilo de la Roma y Grecia antiguas iban a evocar el poder y respeto a la autoridad política local; además de alimentar el sentimiento de progreso característico de aquel imaginario liberal.

\section{EL PALACIO MUNICIPAL: ¿LUJO O NECESIDAD?}

\section{El diseño original sufre modificaciones (1878-1924)}

Tal como se observa en la Figura 3, del diseño de la fachada elaborada por el ingeniero Runnebaum ${ }^{6}$ en 1878, el Palacio Municipal de San Ramón estaba pensado con un estilo neoclasicista desde un inicio.

Contaba con rasgos muy sobrios, con un balcón sostenido por cuatro columnas y dos columnas más en la entrada, al igual que en el primer piso; así también, muestra doce ventanas frontales. En la entrada no había pórtico, las líneas en general eran muy rectas, no hay derroches decorativos ni en las columnas ni en el friso o el frontón; la única variante a la sobriedad generalizada es el efecto que buscaba con la revelación de los ladrillos o las piezas de mampostería a utilizar, que enmarcaban la entrada y los costados del edificio.

En el transcurso de los cuarenta años que se tarda para la conclusión de la obra, la edificación cambió muchas de sus características debido a los problemas presupuestarios que atravesó la municipalidad, pues era una obra bastante ambiciosa en comparación con las rentas que poseía el gobierno local. Sin embargo, conserva su esencia de neoclasicismo sobrio aún en la actualidad, con una mezcla de evocaciones dóricas y jónicas, como se verá a continuación. Desgraciadamente, ni siquiera se había podido finalizar la construcción cuando se produjo el terremoto del 4 de marzo de 1924, con el que la segunda planta del edificio quedó sumamente dañada, por lo cual en un cabildo abierto se acordó derribar lo que quedaba y 


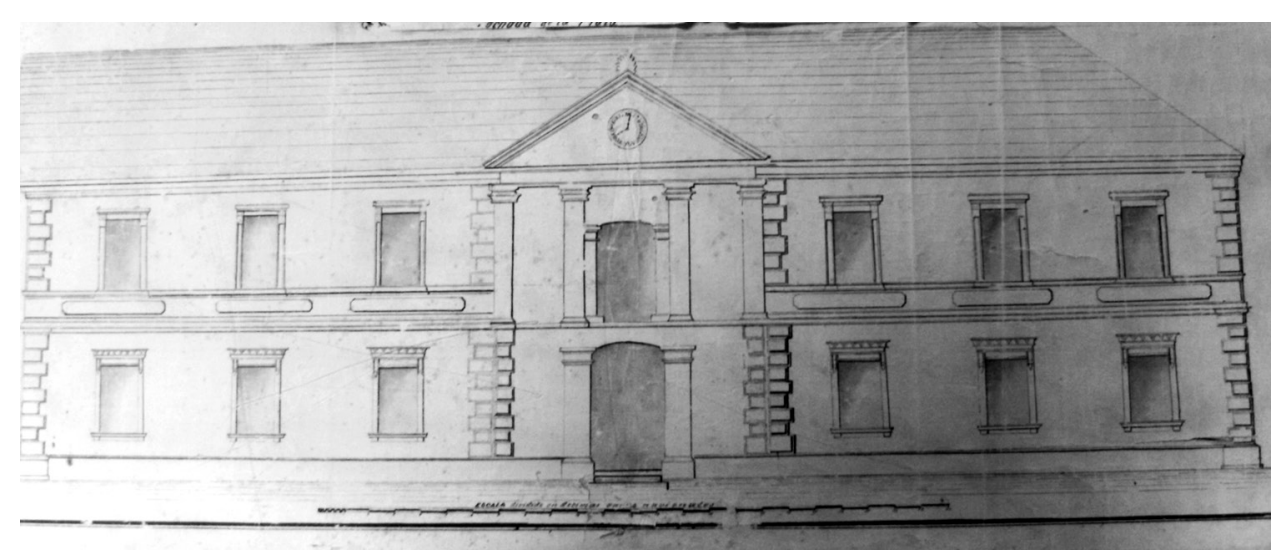

Figura 3. Plano inicial del Palacio Municipal de San Ramón. (1878).

Fuente: Museo de San Ramón. Fotografía.

dejar el Palacio funcionando en una sola planta; posteriormente, esas oficinas se trasladarían y seguiría albergando solo la cárcel del cantón por un tiempo; mientras que ya en la segunda mitad del siglo XX fue el espacio usado para la primera Sede Regional de la Universidad de Costa Rica, y en la actualidad funciona en este edificio el Museo Regional de San Ramón.

Descripción del edificio erigido: ubicación, distribución de la estructura, estilo arquitectónico y materiales utilizados

Por medio del acuerdo municipal del $1^{\circ}$ de marzo de $1878^{7}$ se estableció edificar el Palacio Municipal al norte de la Plaza Principal, ocupando menos de un cuarto de manzana, y advirtiendo que se elaboraría de cantería, debido a que existía "facilidad para conseguir los materiales y fondos para llevarlo a cabo"; además, ya estaba elaborado el plano por parte del ingeniero alemán Cristoph Conrad Runnebaum, conocido como "don Carlos". En realidad, como se mostró anteriormente (Figura 3), el "plano" en cuestión consistía en un dibujo de la fachada que tendría el edificio, lo cual varió considerablemente al momento de tener que materializarlo.

No existen versiones en planta del edificio para los años finales del siglo XIX, pero sí para el periodo en que se trató de completar el proyecto, cuando en 1918 se hizo un levantamiento por parte de Guillermo Gargollo en vista de la orden dictada desde el Ministerio de Fomento ${ }^{8}$ para evaluar la obra y con la intención de procurar su conclusión. Gargollo anotaba respecto al edificio la siguiente leyenda como encabezado del plano: 
Plano del Palacio Municipal de San Ramón. Levantado por Gmo. Gargollo el 14 de octubre de 1918, indicando la nueva distribución de los departamentos. En el caso de que se acuerde su terminación toda la parte de la izquierda del vestíbulo está inconclusa, faltando solamente, pisos, cielos, puertas y ventanas. ${ }^{9}$

El plano levantado en el siglo XX nos permite actualmente tener una idea clara de los aposentos y la distribución en general (en forma de C) con que contaba el Palacio Municipal, ya que, al carecer de material fotográfico sobre la parte interna del edificio, solamente las descripciones de Gargollo y la lista de materiales ${ }^{10}$ empleados en la obra nos remiten un poco a su apariencia interior.

Tal parece que esa nueva distribución a la que hacía referencia Gargollo estaba ligada a la funcionalidad que ya en el siglo XX debía prestar el edificio, con espacios que fuesen más allá de solamente albergar al cuerpo municipal, pues en él se concentraban también el correo, el telégrafo y el dormitorio de los policías, de manera que agrupara los servicios que permitían la comunicación a larga distancia y con las demás autoridades laicas.

Tal como se muestra en las Figuras (3 y 5), la edificación constaba de dos plantas, antes del terremoto de 1924. La primera planta poseía en sus paredes columnas adosadas (especie de pilastras), un pórtico que salía hasta la calle, frente al vestíbulo, con una puerta amplia de dos hojas, formando en la parte superior del marco de esta un arco rebajado. Los dos pares de columnas del pórtico se caracterizan por un fuste y capitel de tipo dórico y una basa de orden jónico; estos rasgos se repiten en las columnas del balcón principal - sobre el pórtico- en la segunda planta; sin embargo, en medio de ellas se erige otra estructura formando un arco lateral de medio punto hasta unirse con la pared; pero además, desde la base de la columna interior del balcón, se eleva otra formando un arco frontal.

Dichos arcos podrían haber tenido una función meramente decorativa o más probablemente

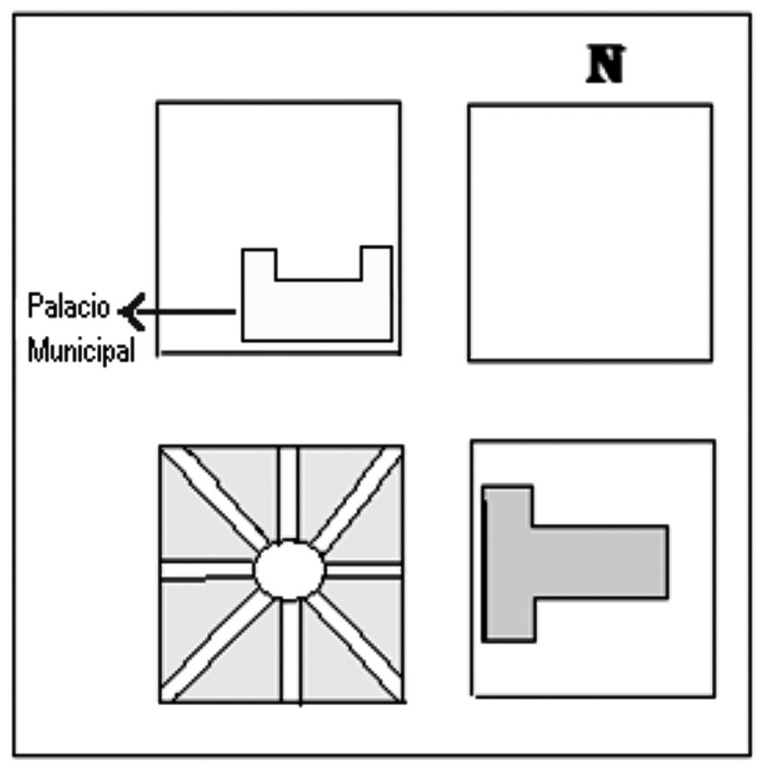

Figura 4. Croquis de ubicación del Palacio Municipal. Fuente: Elaboración propia. 


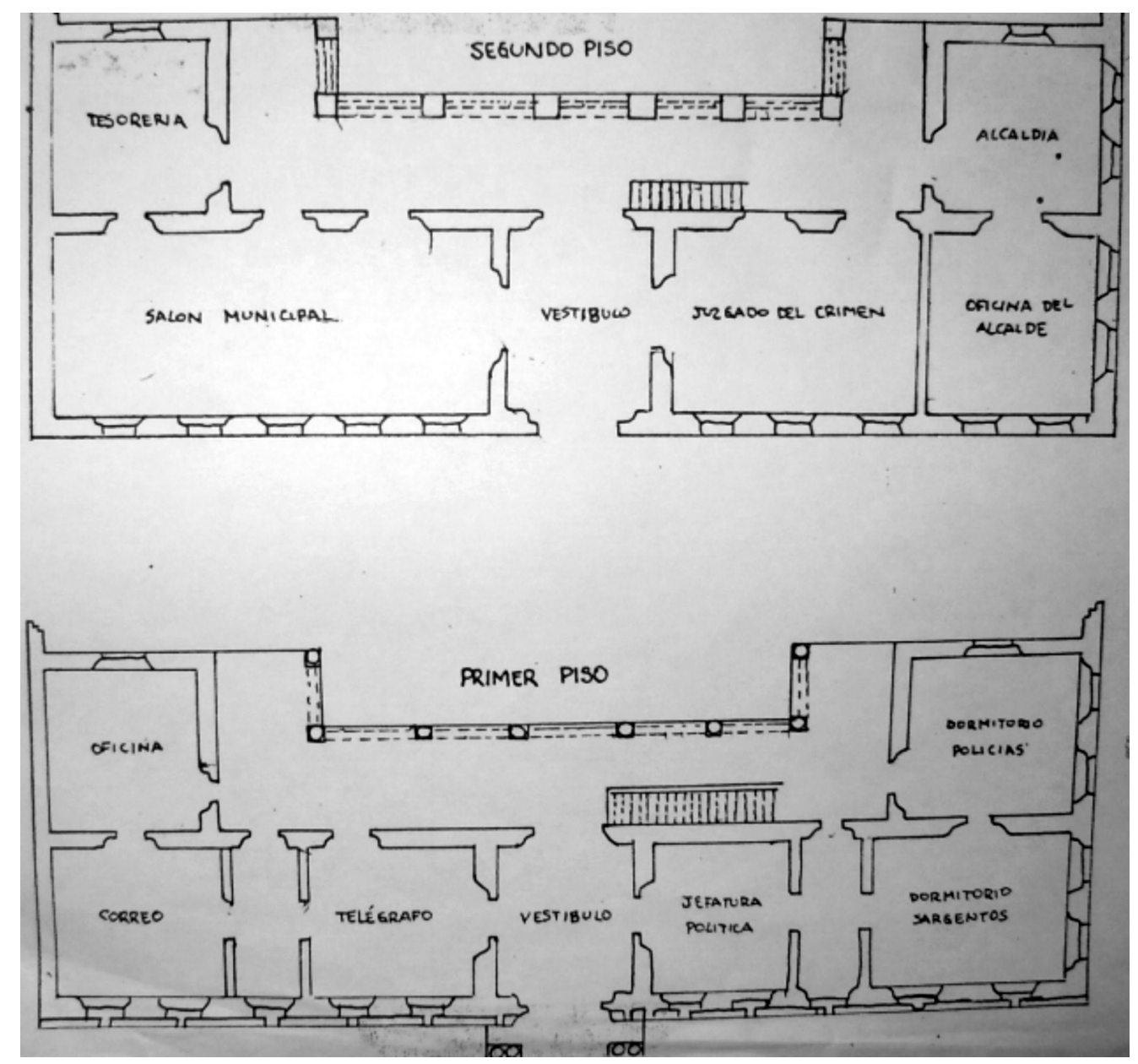

Figura 5. Levantamiento Planta-Palacio Municipal de San Ramón. (1918).

Fuente: Museo de San Ramón. Copia del original.

funcionar como contrafuertes volantes para darles rigidez a las paredes y contrarrestar las fuerzas que generasen al ser de mampostería, además de funcionar como sostén del peso ejercido por el frontón. Este último presenta un orificio circular vacío, al parecer nunca se instaló el reloj que debía llevar de acuerdo con el plano de 1878. Posee también un friso sencillo y parece que rematando el frontón iba una acrótera de tipo jónico.

Contaba con veinte ventanas (de dos hojas y con vidrios) en el frente, distribuidas de cinco en cinco hacia cada lado de la entrada en la primera planta y del balcón en la segunda. Los balcones de cada ventana tenían una balaustrada (de la misma manera que el balcón central), aunque los del lado oeste de la fachada se terminaron - al igual que muchos detalles de esa ala del edificio- poco antes de ser destruidos por el terremoto. Al costado este contaba con ocho ventanas, 
cuatro en cada piso, al costado oeste no poseía ventanas y en el sector norte tenía cuatro ventanas, dos por piso en las paredes salientes. Los marcos superiores de las ventanas siguen el estilo de arcos rebajados.

Se encontraba dividida en seis aposentos en el primer piso: de izquierda a derecha una oficina, el correo, el telégrafo, la jefatura política, dormitorio de sargentos y dormitorio de policías. En la segunda planta se ubicaban cinco aposentos, la tesorería, el salón municipal (con el doble del tamaño) el Juzgado del Crimen, la oficina del alcalde y la Alcaldía. Para acceder al segundo piso, debían subir por las gradas que estaban en el corredor, al lado derecho después del vestíbulo, frente al patio trasero. ${ }^{11}$

En lo que respecta a los materiales con que fue construido el Palacio Municipal, va adecuándose a los avances de la época, como lo eran la teja de hierro (placas de zinc) y el concreto armado, según lo manifiesta Altezor (1986).

\section{El edificio va acercándose a su culminación alrededor de los años de 1922-1923}

La base sobre la que se erige está compuesta de arena y cal. Sus paredes de calicanto hechas en el siglo XIX fueron recubiertas con repello y pintadas; no obstante, a raíz del largo periodo que tardó en terminarse, los arcos y los balcones exteriores se construyeron en "cemento armado", es decir, en concreto armado. ${ }^{12}$

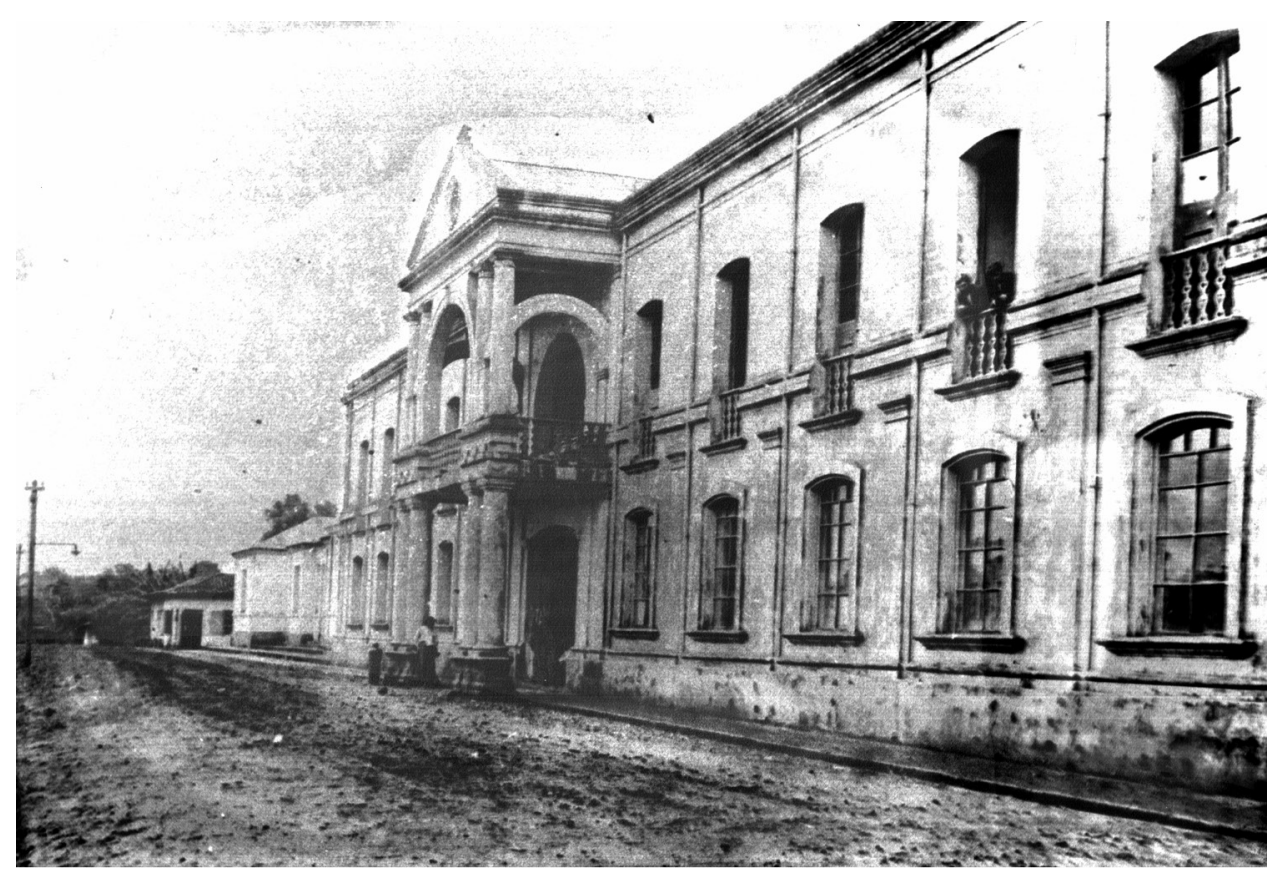

Figura 6. Palacio Municipal de San Ramón. (Año desconocido).

Fuente: Museo de San Ramón. 
Hay uso de maderas en los cielos, el piso, las ventanas y las puertas, estas últimas de cedro. Un sector del piso, el del corredor, tenía mosaicos, además en un inicio el patio era alumbrado con lámparas de canfín, pero ya para 1922 contaba el Palacio con ocho lámparas eléctricas y de acuerdo con Gargollo "el citado Palacio es una obra de verdadero mérito, no por su arquitectura que tiene defectos, si no por su sólida construcción de calicanto bien trabajada...".13

\section{El costo de la obra}

¿Sería necesario llevar a cabo un proyecto de tal envergadura para un pueblito que estaba apenas iniciando su vida como ente autónomo del poder alajuelense? O ¿sería esta edificación, más bien una muestra de la creciente diferenciación socioeconómica que empezaba a plasmarse en la localidad a través del poder político?

Para responder fielmente a esa interrogante sería fundamental llevar a cabo un trabajo de investigación mucho más amplio y exhaustivo, pero en lo que resta de este ensayo trataremos de empezar a perfilar la respuesta.

De acuerdo al presupuesto establecido en el Acta Municipal de San Ramón del 23 de marzo de 1923 (libro 42), se determina que para concluir "la parte vieja" del edificio se necesita una suma de $\$ 8.478 .20$ y para construir "la parte nueva", $\phi 17.939 .95$; es decir, un total de $\phi 26.418 .15,{ }^{14}$ todo esto adicional a la inversión que se había hecho desde 40 años atrás (un gasto de alrededor de $₫ 4.326 .95^{15}$ ), pues ya lo que faltaba eran algunas puertas y ventanas por colocar, el pago de los carpinteros, arreglar los repellos y la acera, hacer algunas columnas, balaustradas y paredes interiores.

Es decir, por mucho tiempo el Palacio Municipal permaneció como una especie de cascarón imponente en el campestre San Ramón. Su interior nunca terminado no sería tan impresionante, pero su exterior, el que era contemplado por cualquiera, propio o extraño, daba la impresión de estar en otro lugar y en otro momento. Era un lujo, sí que lo era, pero uno que no pudo darse tan pronto como se esperaba. Tal vez no fuese visto por los ojos del experto como una maravilla arquitectónica, pero su posición espacial privilegiada y la función a la cual sirvió esa estructura, hace de este edificio municipal un monumento para cualquier ramonense en el cambio del siglo XIX al XX. Y ese discurso que se articula en la estructura del Palacio Municipal es lo que se analiza en el siguiente apartado. 


\title{
TRES GRANDES DE CARA AL PUEBLO: LA ARQUITECTURA, LA IDEOLOGÍA Y EL JUEGO DEL PODER POLÍTICO-ECONÓMICO
}

\section{Neoclasicismo, democracia liberal y progreso}

En un momento en que la razón y la ciencia se convierten en la explicación del universo, los grandes pensadores del periodo clásico y las obras que se conservan de aquel momento se tornaban en la manifestación más acertada del orden mediante la simetría estricta y la pureza de las composiciones geométricas en la construcción arquitectónica, ya que los arquitectos neoclásicos buscaron los efectos de la solidez y la permanencia, de la solemnidad y la rigidez, de la evocación serena y silenciosa de ese mundo arcaico (Honour, 1982).

El neoclasicismo surgido en Europa a finales del siglo XVIII se deja sentir con mayor fuerza en Hispanoamérica a partir de la segunda mitad del siglo XIX, asociado con el pensamiento liberal en su afán democratizante y de la mano de los positivistas alzando la bandera del orden y el progreso social.

Es así como el Palacio Municipal de San Ramón con su corte neoclasicista, se convirtió en una más de las formas de manifestación ideológica de la época. Siguió una tendencia - eso sí- poco común en tanto es un edificio pensado para albergar un cuerpo municipal, es decir un gobierno local, mientras lo característico era que se convirtiera en estilo distintivo del poder del Gobierno Nacional, tal como nos lo presentan Sanou y Quesada (1998):

\begin{abstract}
En las primeras décadas del siglo XIX, los estilos dominantes fueron el italianizante de los palacios y villas y el clásico griego. Este último fue tomado como símbolo de la república y de la democracia en el hemisferio occidental, debido a la atención que en el mundo se le dio a la independencia de Grecia ocurrida en 1827. No hubo una tendencia única dentro del neoclásico para construir las casas de gobierno; sin embargo todas ellas tuvieron en común, la utilización de cortiles, el juego de superficies planas y pórticos, la elegancia y fastuosidad de sus interiores y su ubicación estratégica con respecto a la plaza mayor.
\end{abstract}

Si observamos las fotografías del Edificio Municipal de San Ramón, su fachada se convierte en el lenguaje del poder político de la época, coincidiendo su construcción con el ascenso de los liberales al poder costarricense. Esta edificación hace eco de todo un proceso histórico que va más allá de la mera representación estilística, ya que nos remite inmediatamente al análisis de una mentalidad dominante que llega a instalarse inclusive en zonas que son aún 
de difícil acceso en la Costa Rica del siglo XIX, tal como mencionábamos páginas atrás.

\section{LA MUNICIPALIDAD Y SU PAPEL EN LA COMUNIDAD RAMONENSE}

Para comprender mejor el proceso que se articula alrededor del Palacio Municipal, cabe resaltar que con la restauración de las municipalidades (18671876) y las nuevas políticas y estrategias de la Dirección General de Obras Públicas, que estaban al servicio de las obras materiales de los gobiernos liberales, se creó el clima propicio para el desarrollo de las principales tipologías arquitectónicas. Además con la descentralización de las Obras Públicas hubo un auge en las funciones municipales, las cuales se fortalecieron durante el régimen de Tomás Guardia, al disponer de la recaudación de algunos impuestos y tasas municipales (Sanou y Quesada, 1998, p. 224), lo que explica la autonomía con que comienza a trabajar la municipalidad ramonense en ese aspecto a partir de 1877 . No obstante, el presupuesto ordinario que se otorgaba a los gobiernos locales dependía del gobierno provincial, en este caso de Alajuela (Castro y Willink, 1989).

Ese contexto nos permite comprender también por qué se le hace tan complicado al pueblo de San Ramón completar la obra, que por sus características demanda un alto presupuesto, no disponible -obviamente - para un gobierno local, que prácticamente se estaba manteniendo con lo que se le dispusiese y lo que por su cuenta pudiese recolectar en impuestos; situación que tiene como agravante el gasto del gobierno nacional en el impulso que se estaba dando al mismo tiempo a la construcción del ferrocarril, el correo y el telégrafo.

Para ilustrar la situación de las finanzas con las que podía costearse la construcción del edificio considérese la Tabla 1.

A pesar de carecer de la información correspondiente a los primeros años de funcionamiento municipal, es perceptible la incapacidad del municipio para terminar por sí solo la obra, pues inclusive el ingreso total en 1920, es mucho menor que el costo presupuestado para concluir el edificio. Recordemos que este era de aproximadamente $\phi 26.418$. Y es que es hasta en 1914 cuando se registra una donación considerable del Estado ( $₫ 400^{16}$ ), en el gobierno de Alfredo González Flores, para avanzar con las obras.

Además, existían otros gastos que debía solventar el gobierno local, en este caso sí se encontró el dato correspondiente a un año anterior, 1877 (un total de $ф 2.772$ ); sin embargo, no es posible contrastarlo con los ingresos. Como se muestra en la tabla 2, en 1896 hay un saldo positivo de casi la mitad del presupuesto ordinario 


\section{Tabla 1}

INGRESOS DE LA MUNICIPALIDAD DE SAN RAMÓN, PRESUPUESTO ORDINARIO

\begin{tabular}{lcccccc}
\hline \multicolumn{1}{c}{ AÑO } & & & & & \\
\multicolumn{1}{c}{ RUBRO } & 1896 & $\%$ & 1911 & $\%$ & 1920 & $\%$ \\
\hline Ingreso total & 6.219 & 100 & 12.833 & 100 & 15.580 & 100 \\
Alquileres & 1.075 & 17,2 & 3.288 & 26,0 & 4.620 & 29,7 \\
Patentes & 1.649 & 27,0 & 3.000 & 23,0 & 5.000 & 32,1 \\
Impuestos & 2.500 & 40,1 & 3.360 & 26,2 & 2.350 & 15,1 \\
Cañería & - & - & $* 2.690$ & $* 21,0$ & 1.440 & 9,2 \\
Alumbrado público & 480 & 7,6 & & & 1.500 & 9,6 \\
Policía & 280 & 4,5 & 395 & 3,0 & 20 & 0,1 \\
Venta de tierras & 100 & 1,5 & - & - & - & - \\
Otros & 135 & 2,1 & - & - & 650 & 4,2 \\
Ingresos distritos menores & - & - & 100 & 0,8 & - & - \\
\hline
\end{tabular}

Nota: *Incluye alumbrado. La autora se basa en actas municipales. Fuente: (Vázquez, 1982, p. 34).

\section{Tabla 2}

EGRESOS DE LA MUNICIPALIDAD DE SAN RAMÓN, PRESUPUESTO ORDINARIO

\begin{tabular}{lcccccc}
\hline \multicolumn{1}{c}{$\begin{array}{c}\text { AÑO } \\
\text { RUBRO }\end{array}$} & 1896 & $\%$ & 1911 & $\%$ & 1920 & $\%$ \\
\hline $\begin{array}{l}\text { Egreso total } \\
\text { Sueldos }\end{array}$ & 3.649 & 100 & 18.833 & 100 & 13.240 & 100 \\
Higiene, población, arreglo & 1.992 & 55,0 & 2.674 & 21,0 & 4.896 & 37,0 \\
de calles & 130 & 3,5 & 5.729 & 44,5 & 300 & 2,2 \\
Cañería & - & - & N.D. & N.D. & 500 & 3,3 \\
$\begin{array}{l}\text { Alumbrado } \\
\text { Matadero }\end{array}$ & 360 & 9,7 & N.D. & N.D. & 4.000 & 30,0 \\
$\begin{array}{l}\text { Subvenciones a } \\
\text { instituciones }\end{array}$ & 50 & 1,4 & N.D. & N.D. & N.D. & N.D. \\
$\begin{array}{l}\text { Protección social } \\
\text { Reparación de edificios }\end{array}$ & 252 & 6,8 & 780 & 6,5 & 540 & 4,1 \\
municipales & 840 & 23,0 & - & - & 600 & 4,5 \\
\hline
\end{tabular}

Nota: N.D.: No datos. La autora se basa en actas municipales. Fuente: (Vázquez, 1982, p. 143). 
anual; no obstante, al parecer no se empleó parte de ese dinero en avanzar con las obras del Palacio Municipal y no se detalla su uso.

Existe la probabilidad de que los montos destinados por la municipalidad para continuar con la construcción del Palacio fueran los obtenidos por las ventas de terrenos, que en un inicio avanzan regularmente, pero como pudimos observar en el primer cuadro, ya para la última década del siglo XIX no se registran. Un documento que podría respaldar esta hipótesis es una petición de la comunidad al Ministro de Gobernación hecha en 1884, en la cual se alega que "siendo obligación de los municipios procurar el bien procomunal y el adelanto de las poblaciones donde se hallan establecidas, esta consideración, y el interés que esta población entera tiene por la conclusión del Palacio Municipal yá muy adelantado en esta villa, inducen á este Municipio á suplicar se le concedan dos leguas de tierra", ${ }^{17}$ con la idea de vender una y dar la otra a los pobres; no obstante, dicha solicitud fue denegada.

Y es que ya en 1881 se mostraban las dificultades que se tenían para cumplir con el pago de los trabajadores del edificio, ${ }^{18}$ por ejemplo, en Acta Municipal del 15 de julio de dicho año, se lee que "con presencia de la baratura (de los renglones principales) que ha traido [sic] consigo la escasez pecuniaria, y de que las Bentas [sic] Municipales se hallan bastante apuradas se acuerda: que los trabajadores del Palacio Municipal en construcción que hoy ganan doce reales, continúen ganando diez: que los que ganan diez, continúen ganando un peso, y que los que ganan un peso, continúen ganando noventa centavos". ${ }^{19}$

Al parecer, otro de los problemas financieros que afectó la pronta conclusión del edificio fue el carácter prestamista que adquirió la municipalidad hasta mediados de la década de 1880. Este ente daba préstamos desde 50 pesos hasta más de 200 pesos $^{20}$ y muchos de los intereses no se pagaban a tiempo, por lo que los deudores se convertían en un verdadero problema y un elemento desequilibrante en su economía.

\section{Las familias dominantes económica y políticamente}

La inauguración del Palacio Municipal se llevó a cabo en agosto de 1893, en medio de una celebración con "refrescos". Se hizo cada vez más necesario instalar las principales oficinas, para evitar el pago de alquileres, pues por algún tiempo el edificio albergó al Mercado Municipal.

En el grupo de miembros municipales sobresalen ciertos apellidos a través de los años, de los cuales algunos tienen además cierta trascendencia en el curso político nacional. Por ejemplo, los señores Paulino y Juan Vicente Acosta, este último padre de Julio Acosta fue el Presidente municipal en 1877-1878-1880 y Jefe 
político en $1885,{ }^{21}$ era destacado comerciante de la zona, luego Julio y su hermano tomaron un papel importante a raíz del conflicto con los Tinoco.

Otra familia, además de los Gamboa (que formaron parte también por mucho tiempo del cuerpo municipal), ${ }^{22}$ con importante participación política y fuerte poder económico, fueron los Valverde, representados en aquel momento por Macario Valverde (padre del Dr. Carlos Luis Valverde) y su suegro Miguel Vega. Posteriormente, un poco más entrado el siglo XX, los Orlich en la figura de Aquileo y Nicolás, calaron en las luchas de las que fue testigo San Ramón durante los años de 1916 a 1919.

De acuerdo con Silvia Castro, en 1916 fue Nicolás Orlich (diputado por San Ramón) quien llevó al Congreso la propuesta de un plebiscito para que San Ramón fuera la cabeza de una nueva provincia, en conjunto con Palmares, San Carlos y Alfaro Ruiz. Tal petición se generaba por la insatisfacción que vivían las autoridades ramonenses respecto al asunto presupuestario que manejaba Alajuela. Así, persuadieron a las comunidades aledañas en su intención y su trabajo rindió frutos en la votación hecha en todos los pueblos, excepto en Palmares, donde el cura local había hecho un trabajo discursivo a favor de los intereses alajuelenses. No obstante, se solicitó dar avance al proceso, pero esta situación coincidió con la llegada de la dictadura tinoquista al poder y el rechazo del proyecto por parte de las nuevas autoridades nacionales (Castro y Willink, 1989, pp. 50-55).

Y durante la dictadura de los Tinoco, miembros de reconocidas familias ramonenses lideraron un grupo de rebeldes que tomaron el resguardo, la oficina de telégrafos y el Palacio Municipal, en 1918; sin embargo, con la entrada de las tropas tinoquistas en la noche del 23 de febrero, muchos de los sediciosos fueron capturados o escaparon entre la montaña hacia el norte (Castro y Willink, 1989; Cambronero, 2001).

Definitivamente, San Ramón se había constituido como un punto de lucha social, de acervo cultural y de prosperidad económica para ciertas familias. Sin duda, un grupo dominante con vínculos de parentesco, muchos de ellos con ascendencia foránea, se estaba consolidado y al cual se le unieron algunos recién llegados como Federico Hopkins, Mariano Figueres, Lucio Herrera, Ángel y Marcelino Losilla (Cambronero, 2001), quienes también arribaron al cantón, pero ya después de 1900 .

Esto nos permite entender el valor y la función social que podía tener un edificio municipal como el que se había intentado construir durante todo ese periodo de apogeo liberal, la conclusión de tal obra era importante para reafirmar ese crecimiento y ese progreso que iba dándose entre los vecinos principales del lugar, era la materialización de esa modernidad que muchos de los extranjeros sí conocían al proceder de países con ciudades más desarrolladas. 
Con la intención de cerrar este apartado, presentamos la descripción que hiciera Moncada, en 1917, sobre ese San Ramón de principios de siglo XX, que tanto interés tenía en conducirse como un centro de poder autónomo:

Rodeado de verdes colinas... las calles como toda ciudad moderna, son rectas, amplias y macadamizadas en su mayor parte. Tiene frente a la iglesia parroquial un hermoso parque, siempre lleno de flores, pacayas y árboles frondosos. Hay además tres plazas en donde por las tardes se divierte cierta juventud.

Entre sus principales edificios citaremos los siguientes: un magnífico palacio que ya está en conclusión, en donde se encuentran instaladas las principales oficinas de Gobierno y Justicia... una iglesia espaciosa... escuelas... un mercado de primera que ocupa casi un amanzana, un hospital de lo mejor... otra iglesia más pequeña llamada del "Tremedal" y un teatro que figura como el segundo de la República...

Abastecida con agua de cañería que viene del Barranca... el empresario norteamericano, Federico Hopkins por contratos celebrados con las Municipalidades suministra luz y fuerza eléctrica a las respectivas poblaciones.

El movimiento comercial y agrícola es muy efectivo. Hay 7 beneficios de café, 13 aserraderos, 2 talleres de mecánica, 197 trapiches, 3 farmacias y varios botiquines, 4 talabarteras, 4 panaderías, 2 ferreterías, 8 fábricas de puros y cigarros, 4 herrerías, 2 hoteles, 5 sastrerías, 2 joyerías, 10 fondas, 4 billares, 4 barberías, 3 caballerizas, 3 máquinas de sacar arroz, 2 máquinas de quebrar piedra... hay otras de hacer breva, 3 de hacer candelas, una de hacer sacos, otra de mecate, otra de jabón, otra de hielo, otra de hacer fideos y por último una de hacer aguas gaseosas, refrescos y siropes... hay un total de 114 establecimientos, entre los que sobresalen el de los señores Orlich Hermanos, el de don Rodolfo Gamboa e Hijos, el de don Alfredo Salazar, el de don Angel Losilla, el de don Julio Hernández y el de don Macario Valverde...

Circula semanalmente el periódico "El ramonense" editado en la imprenta de los señores Acosta... (Cambronero, 2001, pp. 31-34)

Sin duda, un texto apologista era lo que escribía Moncada en aquel momento, pero al ser de la época, nos permite observar la manera en la que se concebía el Palacio Municipal, quiénes formaban el grupo dominante, visualizar los cambios del emplazamiento y el avance de servicios y técnicas modernas. Pero también el lenguaje había cambiado, ya no era una plaza lo que había frente a la iglesia y al Palacio Municipal, sino un parque, dispuesto para el disfrute y en torno al cual se erigen las dos fuerzas: el Estado y la Iglesia, que terminaban orientando la vida cotidiana del lugareño, de forma que, 
queriendo o no, la función didáctica del poder estatal en un Palacio Municipal neoclasicista salía a relucir.

\section{CONCLUSIONES: UN LENGUAJE TRAS UNA FACHADA}

Tras este breve recorrido por el centro ramonense entre 1877 y 1924, de la mano del Palacio Municipal, se hizo notable cómo una estructura transmite un lenguaje, aun cuando sea una simple fachada sin concluir, porque tras ella se mueven intereses e ideas que le dan la connotación histórica y permiten reconstruir todo un proceso dinámico.

De manera que el edificio no solamente se articulaba como tal, sino como un medio de imponer el pensamiento de la época - un nexo con el resto del mundoen su función didáctica a un pueblo aún en ciernes.

Este neoclasicismo, de acuerdo con sus rasgos arquitectónicos, era evocador de la cultura griega y romana, pero a su vez del poder económico en aumento y de la ideología liberal que marcaba ese imaginario en el tránsito del siglo XIX al XX, que alimentaba la cotidianidad de una élite local en ciernes, haciéndose partícipes de las transformaciones y pugnas vividas a nivel nacional.

Además, como se ha visto acá, la ostentación buscada para el sitio donde se instauraría la autoridad - el poder - tuvo demasiados obstáculos, fundamentalmente en su financiamiento, no solo por la renuencia del gobierno nacional para contribuir en la construcción, sino también debido a las modificaciones en los derechos o disposiciones correspondientes a las municipalidades, ya que con ello algunos recursos que ingresaron en un primer momento, hacia finales del siglo XIX dejaron de ser percibidos, con lo que la conclusión definitiva de la obra se tornó casi en una odisea.

Una edificación como lo fue esta, de acuerdo a sus dimensiones y ubicación, en un espacio aún remoto, es muestra también de la fuerte inmigración que recibió esta zona hacia finales del siglo antepasado, y del nivel sociocultural de esos habitantes. Para los ramonenses, el Palacio Municipal se convertiría en un elemento identitario, en un baluarte en luchas políticas, en un orgullo y representación de la "modernidad", que se resaltaba junto con los otros adelantos que iban configurando al cantón de San Ramón.

La arquitectura, el estilo, sin un contexto no significarían nada; no obstante, los pueblos olvidan, no valoran esfuerzos ni lecturas de otro momento que no sea el actual, y es precisamente eso por lo que debe luchar el historiador, por abrirse a otro tipo de lecturas, por dar a conocer una comunidad, país o región, aunque sea 
una parte de su pasado, que al fin y al cabo es el que permite comprender nuestro presente.

\section{CITAS Y NOTAS}

1 La investigación fue presentada como ponencia en el 2010, en el Simposio Interinstitucional de Historia Regional: El caso de las regiones Occidente y Norte de Costa Rica: 1821-2010. Y el trabajo había sido realizado en el 2009 como parte del curso de Iconografía Liberal desarrollado en la Maestría Académica en Historia.

Este documento corresponde con un trabajo realizado por y para el mismo Museo de San Ramón. Se encuentra disponible en el Archivo del Museo de San Ramón. Documento número 0528.

2 (Archivo del Museo de San Ramón, 1855-1856). Petición hecha al Gobierno de la República y respuesta de este proclamando el Decreto XLII por el Presidente Juan Rafael Mora.

3 De acuerdo con la publicación en línea que posee la Municipalidad de San Ramón, Historia del cantón de San Ramón. Recuperado de http://www.sanramoncr.com/historia.html/

4 Ver más adelante, en el cuarto apartado, las pugnas políticas en las cuales esta familia ramonense de gran peso en el municipio se ve involucrada.

"El 6 de julio de 1878 las gentes se desbordan en las calles, desfilan con la alegría de la banda militar, porque se está celebrando la iluminación del pueblo con faroles colocados en las esquinas. Este alumbrado permanecerá de 6 de la tarde hasta que aparezca el alba, y como todo servicio público cuesta dinero, tendrán los usuarios que pagar dos centavos por cada vara de su propiedad, por concepto de alumbrado público.

Este encender y apagar los faroles está a cargo de don Ramón Picado, magnífico colaborador del pueblo ramonense" (Quesada, 1996, p. 25).

6 De acuerdo a los datos manejados por el Archivo del Museo de San Ramón, Cristoph Conrad Runnebaum, conocido como "don Carlos", nació en Dorpel, Alemania, el 19 de marzo de 1846. Hijo de Hermann Heinrich Runnebaum y Whilhelmine Collage zur Collage Schweers. Con su padre que era geómetra real aprendió los rudimentos de la ingeniería, siendo más su especialidad el diseño y la agrimensura. En Costa Rica, el Gobierno lo contrató para elaborar un mapa general, el cual fue realizado por él y otros colaboradores. Se casó en Esparza en 1881 y regresó a Alemania en 1895. 
7 De acuerdo con (Vásquez, s.f.), en documento facilitado por el Archivo del Museo de San Ramón. Número: 117-S.R.

8 Estaba incluido como parte de una carta dirigida en respuesta al Ministro de Fomento. San José, 22 de octubre de 1918. Se puede acceder en: (Archivo Nacional de Costa Rica, 1918-1921). Y comprende la colección de correspondencia sobre la finalización de la obra (1918-1921).

9 (Archivo Nacional de Costa Rica, 1918).

10 Facilitado por (Archivo del Museo de San Ramón, 1982).

11 De acuerdo con la copia del plano levantado, existente en (Archivo del Museo de San Ramón, s.f.).

12 Es importante reconocer el porqué de los arcos en concreto armado, ya que buscando la pervivencia del edificio ante los embates sísmicos se suponía que este material al formarse como "estructura monolítica, permitía resistir las tensiones horizontales mucho más eficazmente que las construcciones tradicionales de albañilería con sus elementos resistentes aislados" (Altezor, 1986, pp. 115-116).

13 (Archivo Nacional de Costa Rica, 1918-1921). Esa fue la opinión del ingeniero Gargollo de acuerdo a su inspección.

14 Según información facilitada en (Archivo Nacional de Costa Rica, 1918-1921).

15 Aunque en el documento las cantidades aparecen con el signo de colones, muy probablemente los montos fueran dados más bien en pesos nacionales. Ver: (Archivo del Museo de San Ramón, 1982).

16 Datos obtenidos de la información facilitada en el Archivo del Museo de San Ramón. Documento número117-S.R.

17 (Archivo Nacional de Costa Rica, 1884). Esta petición curiosamente está firmada a nombre de Fadrique Gutiérrez, sin embargo, no fue posible averiguar si efectivamente era el escultor Gutiérrez.

18 En un inicio (1881), el director de la obra fue Manuel Cajina, al que se le pagaban 25 pesos, desglosados en tres semanales, pero más tarde no fue posible reconocer quién continúa a su cargo, hasta que en 1921 aparece el nombre del albañil Jesús Pérez. 
19 Es un fragmento de la discusión y resolución en el Archivo Nacional de Costa Rica. (1881). Actas Municipales de San Ramón.

20 Archivo Nacional de Costa Rica. (1881). Actas Municipales de San Ramón. Folio 7.

21 Archivo Nacional de Costa Rica. Actas Municipales de San Ramón. Ver los años 1877, 1878, 1880,1885 .

22 Fue posible observar esto al contrastar la información de la Municipalidad de San Ramón entre finales del siglo XIX e inicios del XX, en (Archivo Nacional de Costa Rica, 1870-1890) y en (Castro y Willink, 1989).

\section{REFERENCIAS}

Altezor, C. (1986). Arquitectura urbana en Costa Rica entre 1900 y 1950. Costa Rica: Editorial Tecnológica.

Archivo Nacional de Costa Rica. (1818). Sección Planos. 002801. Costa Rica: Archivo Nacional de Costa Rica.

Archivo Nacional de Costa Rica. (1818-1921). Fomento. 6568. Costa Rica: Archivo Nacional de Costa Rica.

Archivo Nacional de Costa Rica. (1870-1890). Municipal. Actas del cantón de San Ramón. Costa Rica: Archivo Nacional de Costa Rica.

Archivo Nacional de Costa Rica. (1884). Congreso. 8710. Costa Rica: Archivo Nacional de Costa Rica.

Archivo del Museo de San Ramón. (1982). Documento número: 04-S.R. Costa Rica: Archivo del Museo de San Ramón.

Archivo del Museo de San Ramón. (s.f.). Documento número: 0025-c2. Costa Rica: Archivo del Museo de San Ramón.

Archivo del Museo de San Ramón. (1855-1856). Documento número: 746-S.R. Costa Rica: Archivo 
del Museo de San Ramón.

Botey, A. M. (1994). Auge y crisis de la economía y el estado liberal: 1890-1940. Costa Rica: Publicaciones de la Cátedra de Historia de las Instituciones de Costa Rica.

Cambronero, J. (2001). San Ramón-su historia. Costa Rica: Autor.

Castro, S. y Willink, F. (1989). San Ramón: Economía y Sociedad 1900-1948. Costa Rica: Universidad de Costa Rica, Sede de Occidente.

Gombrich, E.H. (1999). Estilos artísticos y estilos de vida. En E.H. Gombrich, Los Usos de las Imágenes. Estudios sobre la función social del arte y la comunicación visual. México: Fondo de Cultura Económica.

Ferrero, L. (1986). Sociedad y Arte en la Costa Rica del siglo XIX. Costa Rica: EUNED.

Fonseca, E. y Garnier, J. E. (1998). Historia de la Arquitectura en Costa Rica. Costa Rica: Fundación Museos del Banco Central de Costa Rica.

Fournier, E. (1994). Orígenes de los ramonenses. Familias fundadoras de San Ramón.1843-1900. Costa Rica: Museo Histórico Cultural Juan Santamaría.

González, L. F. (1995). Palacio Municipal de San Ramón. "Reseña histórica del alma política de un pueblo". (Trabajo Comunal Universitario en el Museo de San Ramón) Universidad de Costa Rica, Costa Rica.

Hall, C. (1984). Costa Rica, una interpretación geográfica con perspectiva histórica. Costa Rica: Editorial Costa Rica.

Hernández, H. (1985). Costa Rica: Evolución territorial y principales censos de población 15021984. Costa Rica: EUNED.

Honour, H. (1982). Neoclasicismo. España: Xarait Ediciones.

Malavassi, R. (2012). La arquitectura como símbolo de poder: el edificio Pirie-casa de la ciudad de Cartago, Costa Rica. XI Congreso Internacional de Rehabilitación del Patrimonio Arquitectónico y Edificación. Centro Internacional para la Conservación del Patrimonio. (939-952). 
Malavassi, R. y Jiménez, M. (2006). Evolución histórica de la imagen urbana del cantón de La Unión durante el periodo cafetalero 1841-1963: levantamiento de arquitectura representativa y planteamiento de corredores históricos. (Tesis de Licenciatura en Arquitectura). Universidad de Costa Rica, Costa Rica.

Mielgo, D. (2006). Lenguaje y objeto: materiales para una filosofía de la arquitectura. (Tesis de Doctorado en Filosofía, Universidad Complutense de Madrid). Recuperada de http:// biblioteca.ucm.es/tesis/fsl/ucm-t29562.pdf/

Moya, A. (2008-2009). Arquitectura e interpretación histórica. Diálogos, Revista Electrónica de Historia, 9(2), 312-356.

Pineda, M. (1983). Denuncios mineros en San Ramón. 1884-1935. ¿Un nuevo ciclo minero? Costa Rica: Universidad de Costa Rica, Sede de Occidente.

Quesada, A. (1996). Recordando la historia de mi pueblo San Ramón. Costa Rica: EUNED.

Quesada, F. (2001). En el Barrio Amón: arquitectura, familia y sociabilidad del primer residencial de la élite urbana de San José, 1900-1935. Costa Rica: Editorial de la Universidad de Costa Rica.

Quesada, F. (2011). La modernización entre cafetales: San José, Costa Rica, 1880-1930. Costa Rica: Editorial Universidad de Costa Rica.

Salazar, O. (1990). El apogeo de la república liberal en Costa Rica, 1870-1914. Costa Rica: Editorial de la Universidad de Costa Rica.

Samper, M. (2003). Tierra, trabajo y tecnología en el desarrollo del capitalismo agrario en Costa Rica. Historia Agraria, 29, 81-104.

Sanou, O. (2001). Arquitectura e historia en Costa Rica: templos parroquiales en el Valle Central, Grecia, San Ramón y Palmares 1860-1914. Costa Rica: Editorial Universidad de Costa Rica.

Sanou, O. (2002). Arquitectura de la producción: hacienda cafetalera y cañera, región del Valle de Reventazón y Turrialba, Costa Rica (1890-1930). Costa Rica: Programa de Rescate y Revitalización del Patrimonio Cultural.

Sanou, O. y Quesada, F. (1998). Herencia, ruptura y nuevas expresiones arquitectónicas (18411870). En E. Fonseca y J. E. Garnier. Historia de la Arquitectura en Costa Rica. Costa Rica: Fundación Museos del Banco Central de Costa Rica. 
Silva, A. M. (1991). Estado y politica liberal en Costa Rica: 1821-1940. Costa Rica: UNA-UNED.

Vargas, C. (1989). El liberalismo y la consolidación del estado en Costa Rica, el encuentro entre el estado liberal y la iglesia católica. (Tesis de Maestría en Historia). Costa Rica:Universidad de Costa Rica.

Vargas, G. y Zamora, C. (1999). El patrimonio histórico-arquitectónico y el desarrollo urbano del Distrito Carmen de la Ciudad de San José, 1850-1930. Costa Rica: Ministerio de Cultura, Juventud y Deportes.

Vásquez, I. (1982). Evolución de las municipalidades en Costa Rica. Análisis de caso: Municipalidad de San Ramón. (Tesis de Licenciatura en Historia). Costa Rica:Universidad de Costa Rica.

Vásquez, I. (s.f.). Ficha histórica sobre el Palacio Municipal de San Ramón. Con base en las Actas Municipales de San Ramón. Costa Rica: Museo Regional de San Ramón.

Vera, A. y Sánchez, M. (1985). Lenguaje y símbolo: la arquitectura en encrucijada. Imafronte Revista de Historia del Arte, (1), 23-45.

Viales, R. (2000). Poblar, comunicar y buscar capitales: tres fundamentos de la política agraria liberal en Costa Rica entre 1870-1930. Agronomía costarricense: Revista de ciencias agrícolas, 24(1), 99-111.

\section{ACERCA DE LA AUTORA}

Lissy Marcela Villalobos Cubero: Bachiller en Estudios Sociales. Estudiante de la Maestría Académica en Historia al momento de su realización. Correo electrónico: lissvillacuber@gmail.com 
